
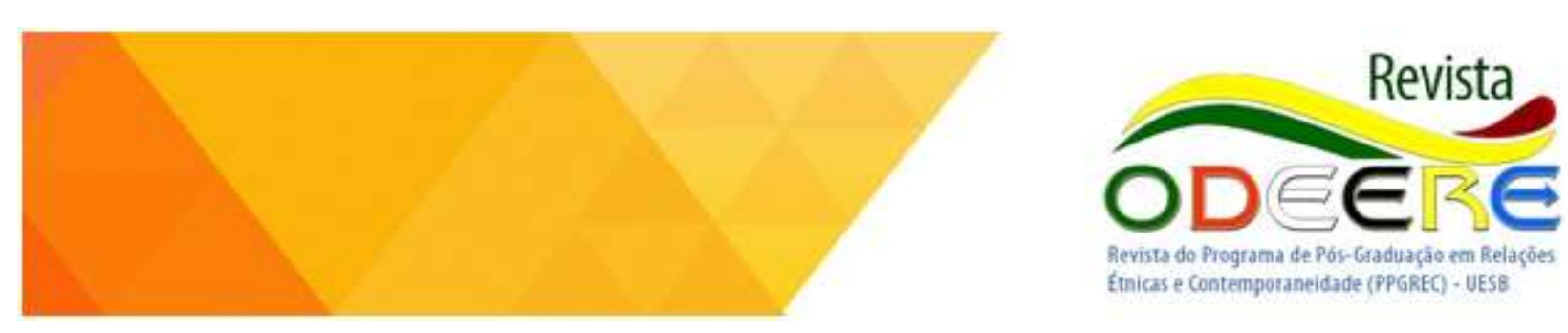

\title{
ENTRE CAROLINAS E
} DANDARAS: reconhecendo histórias e formando para a cidadania $^{i}$

BETWEEN

CAROLINAS AND

DANDARAS:

recognizing stories and forming for citizenship

\author{
Carla de Oliveira Romão \\ Univerisidade Federal de Juiz de Fora (UFJF) \\ petroyf@gmail.com
}

Daiana da Silva

Universidade Federal do Rio de Janeiro (UFRJ) daiana.asilva@yahoo.com.br

DOI: https://doi.org/10.22481/odeere.v4i7.4315

RESUMO: O texto possui como proposta trazer a experiência de duas professoras negras da educação básica que possuem como lócus de sua docência a Baixada Fluminense e que através de suas práticas disputam os significados hegemonicamente atribuídos as mulheres negras e brancas. Além de narrar estratégias metodológicas, queremos formar um diálogo com intelectuais que nos ajudem a repensar e refinar nossa prática docente de forma crítica, assim torna-se indispensável à leitura de feministas negras que nos ajudam a nos localizar quanto à organização do mundo a partir do racismo e do machismo estrutural, além de nos fornecer a visão de que a educação, quando problematizadora, pode ser uma prática libertadora. A partir desta idéia torna-se importante o diálogo, também, com Paulo Freire e sua visão da educação enquanto uma ferramenta potente para transformar as pessoas e assim o mundo. As experiências aqui narradas aconteceram em duas escolas públicas, localizadas em São João de Meriti, no primeiro semestre de 2018; em uma turma de educação infantil e a outra de ensino médio. As experiências práticas procuram realizar um exercício crítico do espaço escolar onde seja possível a convivência com a diferença, permitindo que as alunas e alunos possam ter acesso a outras visões de mundo, oportunizando, desta forma, o acesso a outras histórias onde as mulheres negras e brancas sejam protagonistas e sejam reconhecidas, também, como construtores do país em que vivemos.

Palavras-chave: Educação. Feminismo. Feminismo Negro. Práticas Pedagógicas.

ABSTRACT: The text proposes to bring the experience of two black female teachers of basic education who have the Baixada Fluminense as the locus of their teaching and who through their practices dispute the meanings hegemonically attributed to black and white women. In addition to narrating methodological strategies, we want to form a dialogue with intellectuals that help us to rethink and refine our teaching practice in a critical way, so it becomes indispensable to the reading of black feminists who help us locate the organization of the world from the racism and structural machismo, as well as providing us with the view that education, when problematizing, can be a liberating practice. From this idea it becomes important to also dialogue with Paulo Freire and his vision of education as a powerful tool to transform people and thus the world. The experiences described here took place in two public schools, located in São João de Meriti, in the first half of 2018; in one kindergarten class and the other in high school. The practical experiences seek to carry out a critical exercise of the school space where it is possible to coexist with the difference, allowing the students and students to have access to other world views, thus giving access to other stories where black and whites are protagonists and recognized as builders of the country in which we live.

Keywords: Education. Feminism. Black Feminism. Pedagogical practices. 


\section{Introdução}

O artigo é fruto da experiência de duas professoras negras que atuam na educação básica, possuindo como lócus de sua docência a Baixada Fluminense e que através de suas práticas disputam os significados hegemonicamente atribuídos as mulheres negras e brancas. Neste espaço objetivamos narrar estratégias metodológicas, e formar um diálogo com intelectuais que nos ajudam a repensar e refinar nossa prática docente de forma crítica. Ao fazer isto é importante, também, resgatar nossas memórias enquanto mulheres negras, revivendo nossas experiências escolares e nos sensibilizando a pensar e a produzir, dentro das limitações do espaço escolar, práticas pedagógicas com base na valorização das mulheres e da cultura negra, nesse sentido Nilma Gomes, padagoga, nos traz a seguinte reflexão:

Descolonizar os currículos é mais um desafio para a educação escolar. Muito já denunciamos sobre a rigidez das grades curriculares, o empobrecimento do caráter conteudista dos currículos, a necessidade de diálogo entre escola, currículo e realidade social, a necessidade de formar professores e professoras reflexivos e sobre as culturas negadas e silenciadas nos currículos ${ }^{1}$.

Ao procurarmos descolonizar os currículos entendemos que, por exemplo, nossas experiências escolares foram limitadoras no acesso a história da contribuição da população negra na formação do nosso país, é importante que, enquanto profissionais, e conscientes deste fato tentemos preencher esta lacuna. Ao fazer isto permitimos que nossas turmas tenham acesso a outras histórias, como as das mulheres negras. Com estas práticas podemos construir um arcabouço de estratégias metodológicas descolonizadoras, onde destaquemos a atuação dos povos não nomeados na historiografia oficial, como negros, indígenas e de segmentos também minimizados na sua atuação social como as mulheres.

A tentativa de romper com uma cosmovisão que desqualifica a atuação de vários povos, principalmente aqueles vindos de África e os nativos da terra, na composição da história nacional fez com que ganhasse força às demandas e a atuação do movimento negro no campo da educação pela garantia de direitos, reconhecimento, valorização de nossas histórias e culturas. Um marco desta luta é a medida de ação afirmativa estabelecida na Lei $10.639 / 2003^{2}$, que alterou a Lei 9.394/1996, que define a obrigatoriedade do ensino de história e cultura afro-brasileiras e africanas,

\footnotetext{
${ }^{1}$ GOMES, Nilma Lino. "Relações Étnico-raciais, educação e descolonização dos currículos". Currículo sem Fronteiras, v.12, n.1, pp. 98-109, Jan/Abr 2012a. p. 102.

${ }^{2}$ Se faz importante dizer que a Lei Federal no 10.639/2003 foi alterada pela Lei Lei Federal no 11.645 a fim de ampliar os direitos contemplando o currículo escolar com conteúdos referentes a história e cultura indígena no Brasil.
} 
dando desta forma um grande passo para a descolonização dos currículos, na medida em que pode ajudar a superar e questionar o que Santos, citado por Gomes, ${ }^{3}$ chama de pensamento abissal moderno.

O pensamento abissal moderno é caracterizado pela existência de um saber universal, formado pela cultura européia, que é aceita como verdade e, portanto visível, que não permite a existência de outras explicações, por exemplo, dos povos indígenas, estes sendo considerados invisíveis. Santos ${ }^{4}$ afirma assim que o pensamento abissal moderno é constituído por uma linha onde de um lado fica os saberes legítimos, definidos pelas civilizações colonizadoras e do outro lado da linha ficam os conhecimentos populares, nativos. Os saberes do outro lado da linha são constituídos de invisibilidade, a separação entre estes saberes não permite a convivência igualitária dos sujeitos. Nossas experiências realizadas nas sutilezas do cotidiano escolar têm caminhado para indagar e mexer nessas estruturas profundas de poder e de desigualdade, que se configuram também na formação do currículo escolar.

Outro elemento que contribui com o questionamento das estruturas de poder é a prerrogativa da interseccionalidade, visto que há diversos entrelaçamentos entre as questões de raça/etnia, gênero, orientação sexual e classe, que nos permite a localização dos sujeitos quanto à sua organização no mundo. Assim, a partir do momento que se leva em conta outras intersecções é possível ter uma visão das ausências forjadas pela colonialidade. O termo colonialidade:

faz alusão à invasão do imaginário do outro, ou seja, sua ocidentalização. Mais especificamente, diz respeito a um discurso que se insere no mundo do colonizado, porém também se reproduz no lócus do colonizador. Nesse sentido, o colonizador destrói o imaginário do outro, invizibilizando-o e subalternizando-o, enquanto reafirma o próprio imaginário. Assim, a colonialidade do poder reprime os modos de produção de conhecimento, os saberes, o mundo simbólico, as imagens do colonizado e impõe novos. Opera-se, então, a naturalização do imaginário do invasor europeu, a subalternização epistêmica do outro não-europeu e a própria negação e o esquecimento de processos históricos não-europeus ${ }^{5}$.

Torna-se necessário nesse momento nos fazermos a seguinte pergunta: o que nós mulheres negras e professoras da Educação Básica podemos fazer com essas informações e como podemos usar em favor da educação? No sentido de dar visibilidade a esses pontos Ribeiro ${ }^{6}$, filósofa, traz o conceito de lugar de fala para evidenciar as vozes esquecidas pelo feminismo hegemônico, que

\footnotetext{
${ }^{3}$ GOMES, Nilma. Movimento negro e educação: ressignificando e politizando a raça. Educ. Soc., Campinas, v. 33, n. 120 , p. 727-744, jul.-set. 2012b.

${ }^{4}$ Ibidem.

${ }^{5}$ OLIVEIRA, L. F. e CANDAU, V. M. F. Pedagogia decolonial e educação antirracista e intercultural no Brasil. Educ. rev.. 2010, vol.26, n.1, pp.15-40. Disponível em http://www.scielo.br/scielo.php?pid=S0102$46982010000100002 \&$ script=sci abstract\&tlng=pt, último acesso em 08 de outubro de 2018. p. 19.

${ }^{6}$ RIBEIRO, Djamila. O que é lugar de fala? Belo Horizonte: Letramento, 2017.
} 
seriam as vozes das mulheres negras. Nesse contexto a autora enfatiza o lugar de fala com base no conceito outsider within, produzido por Patricia Collins, socióloga estadunindense, e ao citá-la Ribeiro explica que se traduzido o conceito pode ser entendido como "forasteiras de dentro". Significando que ao mesmo tempo que a mulher negra está dentro reivindicando seu lugar de fala no feminismo, também está fora dada a forma com é tratada. Porém, para Collins ${ }^{7}$ esse ponto de partida marginalizado deve ser usado de forma estratégica para refletir sobre a organização social por meio da localização de olhares distintos.

Sendo assim reconhecemos nossa posição singular dentro da estrutura, uma posição que apresenta possibilidades, mas também limitações. Que nos permite entender que, nós, mulheres negras, quando conscientes dos processos já sinalizados ou mesmo de forma instintiva ressignificamos a educação e abrimos caminhos por meio de produções de saberes/fazeres intelectual. Tendo em conjunto com este fazer a construção de um pensamento feminista, formado por nossas experiências de luta que buscam pensar e contribuir com padrões mais democráticos de educação e com modelos pedagógicos que sejam emancipatórios para todos os indivíduos que frequentam o espaço escolar.

Tanto a compreensão da forma como os saberes são legitimados, através do conceito de pensamento abissal moderno que não permite a co-existência de comosvisões de forma igualitária, como a noção de interseccionalidade, que nos permite complexificar os processos de formação dos indivíduos, e a noção de colonialidade, que no permite entender os processos de ocidentalização da cultura nacional, nos dão base para formular críticas a forma como o conteúdo escolar é apresentado ainda hoje, apesar do avanço já destacado, e se tornam ferramentas importantes para nossa produção docente. Sendo assim, o presente artigo foi construindo tendo essas referências mais pensando também em contribuir com a prática, apresentando possibilidades ao fazer pedagógico. Na próxima seção fazemos uma reflexão sobre a prática docente para em seguida apresentar nossas experiências e por fim formular conclusões sobre o trabalho aqui exposto.

\section{Por uma nova prática docente}

Luiza Bairros, ativista do movimento de mulheres negras, em um de seus textos afirma que "o racismo não pode mais ser praticado sem contestação ${ }^{8 ",}$ ao dizer isso nos informa que na

\footnotetext{
${ }^{7}$ COLLINS, Patricia Hill. Aprendendo com a outsider within: a signifiação sociológica do pensamento feminista negro. In Revista Sociedade e Estado - Volume 31 Número 1 Janeiro/Abril 2016.

${ }^{8}$ BAIRROS, Luiza. Nossos Feminismos Revisitados. In Revista Estudos Feministas, Ano 03, 2ㅇ Semestre, 1995. Pp. 458463. p. 458
} 
atualidade existe contradiscursos que foram formados no interior do movimento negro e no de mulheres negras que nos ajudam a contestar a pseudológica que se esconde nos discursos racistas. Ao mesmo tempo estes contradiscursos resgatam todo o protagonismo feito por mulheres e homens negros na defesa de sua humanidade e na resistência a todas as formas de subalternização.

Sabemos do passado escravocrata de nosso país, entretanto, pouco sabemos sobre as práticas de resistência da população negra, os livros de história, geografia, ciências, matemática, português mais utilizados não trazem a perspectiva negra em seu conteúdo, como afirma Michely Peres de Andrade, socióloga: “Nas aulas de história, sociedades africanas só parecem no contexto da escravidão. Os negros e indígenas brasileiros, por sua vez, ocupam o local do folclórico e do exótico, não sendo representados como sujeitos históricos partícipes ${ }^{9 \prime}$.

A ausência da visibilidade deste protagonismo gera em nossa sociedade a perpetuação dos estereótipos sociais utilizados para população negra desde a época da escravidão. É preciso trazer para a cena social a historiografia da negritude em nosso território, uma história marcada por dor, mas também por muita resistência e movimento, é uma ação que pretende "restituir humanidades negadas $^{10 "}$ como nos diz Giovana Xavier, historiadora, ao falar sobre o feminismo negro, mas que nos serve para pensar na urgência de tratar a temática negra de forma tão importante quanto os outros pilares fundacionais da sociedade brasileira.

As escolas são espaços singulares para a construção de novas culturas em todas as sociedades, pois são espaços que a grande maioria de nós frequentou ou irá frequentar, por isso a crítica a forma como a escola operacionaliza seus discursos deve ser constante. A esta instituição social já foram dirigidas severas críticas quanto ao seu papel de reprodutora das desigualdades sociais, são as chamadas teorias críticas do currículo. Esta teorização possui como marco os anos de 1960 e se caracteriza por produções - que ao contrário das teorias tradicionais marcadas por aceitação, ajuste e adaptação - irão promover a desconfiança, o questionamento e a transformação radical $^{11}$.

Dentre as produções desta época temos a obra de Paulo Freire, A pedagogia do Oprimido, marcada pela compreensão de que o processo educacional deve ser humanista e libertador, que somente através de uma educação crítica poderemos instrumentalizar os oprimidos para a

\footnotetext{
${ }^{9}$ ANDRADE, Michely Peres de. Lélia Gonzalez e o papel da educação para o feminismo negro. In Interritórios - Revista de Educação Universidade Federal de Pernambuco. V.4, N.6, 2018. p. 78.

${ }^{10} X A V I E R$, Giovana. Feminismo: direitos autorais de uma prática linda e preta. In Folha de S. Paulo: Julho de 2017. Agora que são elas (Coluna). Disponível em https://agoraequesaoelas.blogfolha.uol.com.br/2017/07/19/feminismo-umapratica-linda-e-preta/, último acesso em 30 de setembro de 2018.

${ }^{11}$ SILVA, Tomas Tadeu. Documentos de Identidade - Uma introdução às teorias do currículo. Belo Horizonte: Autêntica Editora, 2017.
} 
transformação social. Freire se baseia assim em projeto político emancipador, segundo Gadotti este texto se torna um documento chave para pensar em uma pedagogia centrada "na práxis da aprendizagem da palavra pelo oprimido que se assume como sujeito da sua própria história12", sendo assim uma pedagogia de luta e ao afirmar isso Freire, assim como outros intelectuais, reafirma o papel chave da escola na disseminação de novas concepções sociais, baseadas em práticas emancipatórias.

Entretanto, para que este movimento seja possível é necessário questionar a forma como o espaço escolar transmite seus conteúdos, tanto os oficiais como os não-oficiais, o chamado currículo oculto, caracterizado pelos elementos que não fazem parte do conteúdo oficial, mas que contribuem de forma implícita para a aprendizagem de quem está naquele espaço.

Observamos o poder do currículo oculto quando revisitamos nossas memórias de escola, principalmente de quem não está associado com a visão hegemônica de sujeitos bonitos e aceitáveis, geralmente associado a pessoas brancas. Trindade resgata memórias de mulheres e em seus relatos podemos perceber o poder educador do currículo oculto: "Eu achava que era muito feia, pois nunca tinha gente da minha cor nos murais"; "Uma vez, um menino negro muito bom aluno foi impedido de ser do pelotão da bandeira. A diretoria disse que um branquinho era mais bonito ${ }^{13 " .}$. Trindade traz essas memórias para nos alertar da necessidade de "as ações docentes estarem política, teórica, afetiva e eticamente comprometidas com uma educação sem discriminações, sem racismo, uma educação efetivamente igualitária e acolhedora para todos ${ }^{14 \prime \prime}$.

Sabemos que a postura da professora é uma parte importante dentro do processo educacional, entretanto só ela não faz a escola, a escola é feito por mais elementos que as professoras e este espaço também precisa ser cuidado e valorizado. Freire em entrevista a Folha de São Paulo em 1996 ao falar sobre o Projeto Axé, que trabalha com crianças e adolescentes que estão em situação de rua em Salvador, afirmava da importância de pensar na estrutura do espaço escolar, que estes elementos trazem em si uma pedagogia, que ela pode ou não significar dignidade para quem está ali, seja estudante, docente ou demais profissionais que compõem a escola ${ }^{15}$.

Sendo assim, se torna importante que olhemos para o processo educacional críticos das lacunas existentes, como forma de denunciar e ao mesmo tempo preencher essas lacunas com práticas condizentes com a construção de uma nova sociedade. A ideia de preencher lacunas pode

\footnotetext{
${ }^{12}$ GADOTTI, Moacir. PEDAGOGIA DO OPRIMIDO COMO PEDAGOGIA DA AUTONOMIA E DA ESPERANÇA. In Semana Paulo Freire on line - 50 anos da Pedagogia do Oprimido. 2018. p.01.

${ }^{13}$ TRINDADE, Azoilda Loretto da. Fragmentos de um discurso sobre afetividade. In BRANDÃO, Ana Paula (Coord.a). Saberes e fazeres, v.1: modos de ver. Rio de Janeiro: Fundação Roberto Marinho, 2006. p. 104.

${ }^{14}$ Ibidem. p. 103.

${ }^{15}$ ROSSETI apud PILETTI, Nelson. Estrutura e funcionamento do ensino fundamental. São Paulo: Ática, 2003.
} 
dá a impressão de pequenez, entretanto trazemos para esta cena a potência anunciada por Conceição Evaristo, escritora, ao falar da necessidade de disputar narrativas e utiliza para isso a imagem de escrava Anástacia - negra escravizada que foi forçada a usar uma máscara de ferro até a sua morte - e afirma:

eu tenho dito muito que a gente sabe falar pelos orifícios da máscara e às vezes a gente fala com tanta potência que a máscara é estilhaçada. E eu acho que o estilhaçamento é o símbolo nosso, porque a nossa fala força a máscara. Porque todo nosso processo pra eu chegar aqui, foi preciso colocar o bloco na rua e esse bloco a gente não põe sozinha ${ }^{16}$.

A máscara começou a ser quebrada no campo educacional também pela promulgação das leis 10.639/03 e 11.645/08, que incluem na educação escolar formal a "História e cultura afrobrasileira e indígena" e permite que nós possamos incluir uma versão mais realista da formação do Brasil, uma versão que não inclui só uma perspectiva histórica européia, mas uma versão que incluía de fato a população brasileira negra e indígena que de fato construíram esse país.

Por isso trazemos para o espaço deste artigo duas experiências escolares feitas por docentes atuantes na educação básica como forma de falar de nossa formação de forma crítica, mas também, como exercício prático de como a lei, anunciadas acima, pode ser posta em prática para além de um conteúdo exclusivo da disciplina escolar História, já que nossas práticas são feitas em classes de educação infantil e de sociologia. Destacamos assim a transdisciplinaridade como elemento constituinte desta proposta.

\section{Na prática...}

\section{Educação Infantil}

De acordo com as Diretrizes Curriculares Nacionais para a Educação infantil ${ }^{17}$ a criança é considerada sujeito histórico e de direitos que constrói sua identidade, nas interações, relações e práticas cotidianas. Constrói, assim, saberes de forma lúdica: questiona, experimenta, observa, narra, reproduz e produz cultura. A partir disto podemos compreender que as experiências socializadas durante a infância são muito importante, pois são responsáveis pela forma como internalizamos os sentidos, como organizamos o mundo e como construímos nossas identidades,

\footnotetext{
${ }^{16}$ EVARISTO, Conceição. Conceição Evaristo: “Nossa fala estilhaça a máscara do silêncio”. Carta Capital: Maio de 2017. Entrevista concedida à Djamila Ribeiro. 2017. Disponível em https://www.cartacapital.com.br/sociedade/conceicaoevaristo-201cnossa-fala-estilhaca-a-mascara-do-silencio201d, último acesso em 30 de setembro de 2018.

17 BRASIL. Ministério da Educação. Secretaria de Educação Básica. Diretrizes curriculares nacionais para a educação infantil. Secretaria de Educação Básica. - Brasília: MEC, SEB, 2010. Disponível em: http://portal.mec.gov.br/index.php?option=com docman\&view=download\&alias=9769-diretrizescurriculares2012\&category slug=janeiro-2012-pdf\&Itemid=, último acesso 12 de setembro de 2018.
} 
pois desde muito cedo as relações étnicas/raciais e de gênero atravessam a infância despojando em diversas dimensões positivas de nossos semelhantes.

Sabendo que somos sujeitos históricos carregados de emoções, memórias e subjetividades, logo entendemos que para nós que somos mulheres negras e professoras se faz fundamental trabalhar com olhar de sensibilidade e afetividade, pois esses elementos tem um valor pedagógico ligado a produção de conhecimento das mulheres negras que dão sentido a prática pedagogica. E por que houve um prejuízo histórico a forma de amar a criança negra, que precisa sim ser reparado. Como afirma Trindade:

Porque afetividade está relacionada ao gostar de gente, propiciar encontros, contatos, afetos e afetações. Porque afetividade nos reporta ao corpo e porque os corpos são potências, possibilidades, amorosidade. A afetividade é uma manifestação corporal, uma expressão corporal fundamental para os encontros, contatos, para as expressões de desejos, pensamentos individuais e coletivos, de emoções as mais diversas, de sentimentos como amor, ódio, cuidado. Em síntese, a forma, a maneira como estou/sou no mundo afeta o mundo, as pessoas ${ }^{18}$.

Uma marca, portanto, da primeira etapa da socialização na infância deve ser o afeto consigo e com o outro. Logo, o trabalho realizado na turma de Educação Infantil de 4 anos tem como proposta descolonizar os saberes, a partir da relevância do aspecto da afetividade, e nisto a valorização da narrativa das crianças que nos enriquece e são também enriquecidas com novos repertórios afroreferenciados: as mulheres negras e a própria cultura afro.

As situações descritas aqui são resultados de atividades realizadas em uma escola municipal localizada na cidade de São João de Meriti, região metropolitana do estado do Rio de Janeiro, e possui como proposta incluir na rotina das crianças o ato de ouvir e contar histórias protagonizadas de maneira positiva por mulheres negras como Dandara, Marta Vieira e Carolina Maria de Jesus, Maria Felipa de Oliveira. Essas referências nos permitem apresentar elementos que contribuem para uma construção positiva de fortalecimento e pertencimento a uma identidade afro, onde as crianças podem ter contato com narrativas de mulheres que foram e são ativas nas atividades que exercem, seja como uma guerreira em um quilombo ou como uma jogadora de futebol.

A turma de 4 anos possui uma rotina já organizada, mas que de acordo com Barbosa ${ }^{19}$ a rotina não devem ser padronizada, mas sim flexível. Dentro dessa proposta de rotina todos os dias há a inclusão de um tempo para roda de conversa e contação de histórias possibilitando um momento de escuta, interação, troca de ideais. Durante as rodas de conversa, a docente toma como base a fala das crianças referente ao final de semana e a figura das responsáveis, em sua maioria

\footnotetext{
18 TRINDADE, Azoilda Loretto da. Fragmentos de um discurso sobre afetividade. In BRANDÃO, Ana Paula (Coord.a ). Saberes e fazeres, v.1: modos de ver. Rio de Janeiro: Fundação Roberto Marinho, 2006. p. 101.

${ }^{19}$ BARBOSA, Maria Carmen Silveira. Por Amor e por força: rotinas na educação infantil. Porto Alegre: Artmed, 2006.
} 
mulheres negras. Dada a proximidade com 08 de março - Dia Internacional da Mulher - foi planejado como proposta desenvolver mais a respeito das mulheres presente na vida das crianças da turma. Além disso, foi levado como referencial a fim de ampliar o repertório das crianças o livro Extraordinárias - Mulheres que Revolucionaram o Brasil ${ }^{20} \mathrm{em}$ que todos os dias da semana foram realizadas contação de histórias da vida destas mulheres extraordinárias, entre elas Dandara, Marta Vieira, Carolina Maria de Jesus, Maria Felipa de Oliveira, Antonieta de Barros e Nise da Silveira (esta última se deu a partir do pedido de uma das crianças que curiosamente folheava o livro) e o que elas tem em comum com as mulheres presentes na vida das crianças.

Importante ressaltar que foi usado como base de ensino a abordagem teórica metodológica que Petit ${ }^{21}$ chama de Pretagogia, segundo a autora esta abordagem privilegia a experiência de si e dos outros no mundo por meio de auto-reconhecimento afrodescedente e dos valores das culturas africanas, por isso a escolha de trabalhar com as histórias das mulheres negras. Pensando que esta abordagem foi repensada e já não esta sendo planejada de forma objetivada, mas como proposta de descolonização dos saberes em jogo no cotidiano, um dos frutos desse enredo diz respeito a usar a criatividade e a livre escolha para retratar as mulheres apresentadas por meio de desenho de desenho e pintura, permitindo a livre escolha das crianças com as personagens que mais se identificam.

\section{Ensino Médio}

Dentro do conteúdo do segundo ano do ensino médio para a disciplina de sociologia, de acordo com o currículo mínimo organizado e definido pela Secretaria de Estado de Educação do Rio de Janeiro (SEEDUC/RJ) - órgão responsável pela execução da política estadual de educação - temos o tema de Cidadania, Direitos humanos e Movimentos Sociais. A fim de promover uma maior reflexão sobre esta temática nas turmas a docente procurou destacar a atuação de algumas mulheres dentro da história brasileira, mulheres estas que não são nomeadas em nossos livros didáticos, mas que contribuíram ou ainda contribuem de forma ativa para a construção de um ideal de cidadania mais amplo e efetivo para a população brasileira.

Além de promover este reconhecimento ao trabalhar as trajetórias destas mulheres, podemos ver como a ampliação dos direitos da população está ligada a uma luta política feita no interior dos movimentos sociais. E que a reivindicação dos direitos garantidos em nossa Constituição

\footnotetext{
${ }^{20}$ SOUZA, Duda Porto de \& CARARO, Aryane. Extraordinárias - Mulheres que Revolucionaram o Brasil. São Paulo: Ed. Seguinte, 2017.

${ }^{21}$ PETIT, Sandra Haydée. A lei no 10.639/2003: a criação de nova abordagem de formação na perspectiva das africanidades. In Educ. Foco, Juiz de Fora, v. 21, n.3, p.657-684, set/dez, 2016.
} 
é mais que um direito, é um dever, para que possamos efetivar uma sociedade democrática de direito.

Para começar a atividade resgatamos alguns elementos sobre a Revolução Francesa, um marco historiográfico ocidental, e foi aberto um questionamento para as turmas sobre quem foi Olympe de Gouges. A resposta deveria ser a abertura da próxima aula, onde além de explorar a atuação de Olympe de Gouges na Revolução Francesa exploramos o conceito moderno de cidadania. Então, foi proposta a atividade para pensar a cidadania no Brasil onde as turmas se dividiriam em grupos e cada grupo sorteou um nome de uma mulher, uma personagem histórica do Brasil. Esses nomes foram previamente selecionados pela professora através de dois instrumentos: site do Geledes - Instituto da Mulher Negra, organização da sociedade civil que se posiciona em defesa de mulheres e negros ${ }^{22}$, e o livro Dicionário de mulheres do Brasil ${ }^{23}$, onde por opção selecionei uma maioria de mulheres negras, sendo assim as alunas e alunos poderão ter contato com as histórias de vida de: Beatriz do Nascimento, Lélia Gonzalez, Carolina Maria de Jesus, Luiza Mahín, Mãe Menininha do Gontois, Dona Ivone Lara, mas também de Chiquinha Gonzaga, Olga Benário, Rosie Marie Muraro entre tantas outras.

A ideia proposta era que os grupos conhecessem a história desta mulher e apresentassem para a turma em um cartaz que deveria conter: uma foto; uma pequena biografia e nos informar sobre qual foi à atuação desta mulher no cenário político brasileiro, respondendo a seguinte questão: Como ela contribuiu com a construção da cidadania em nosso país? Durante as apresentações foram feitas outras perguntas para os grupos, tais como: você já tinha ouvido falar desta mulher? E foi impactante perceber o desconhecimento por parte de quem já conclui uma grande parte da educação básica sobre personagens importantes para a formação do Brasil e de sua cidadania. Relato aqui uma memória sobre a apresentação de Carolina Maria de Jesus, onde uma das alunas ficou impactada com o fato de nunca ter ouvido falar de uma escritora tão celebre quanto ela e com uma história de vida que em parte se assemelha a história de vida de muitas alunas e alunos que frequentam a escola pública.

Esta é uma atividade que busca literalmente "Restituir humanidades negadas" como já nos disse Xavier $^{24}$ por que traz pertencimento a quem historicamente esteve no limbo, a quem não consegue se vê como formador de uma nação, não consegue se vê e se entender como cidadã e

\footnotetext{
${ }^{22}$ Para maiores informações acessar o sítio https://www.geledes.org.br/geledes-missao-institucional/, último acesso em 09 de outubro de 2018.

${ }^{23}$ SCHUMAHER, Schuma \& BRAZIL, Érico Vital. Dicionário de Mulheres do Brasil. Rio de Janeiro: Jorge Zahar Ed., 2000. ${ }^{24}$ XAVIER, Giovana. Feminismo: direitos autorais de uma prática linda e preta. In Folha de S. Paulo: Julho de 2017. Agora que são elas (Coluna). Disponível em https://agoraequesaoelas.blogfolha.uol.com.br/2017/07/19/feminismouma-pratica-linda-e-preta/, último acesso em 30 de setembro de 2018.
} 
cidadão. E através do resgate de histórias destas personagens podemos ter a dimensão de dois pontos: que a nossa cidadania sempre foi ativa e que a conquista e ampliação dela foi feita por mulheres e homens simples, que vieram de lugares sociais humildes e que alguns deram suas vidas para a melhoria de outras vidas no nosso país.

\section{Conclusão}

Neste artigo promovemos um diálogo com uma perspectiva crítica da educação para evidenciar um sujeito: a mulher negra. Promovendo um reconhecimento deste sujeito como potente, uma potência que é anunciada tanto nas histórias das mulheres que contamos como é uma potência reconhecida nas mães, em sua maioria mulheres negras. Foi objetivo desta prática valorizar a atuação de ambas e promover uma valorização da estética destas mulheres, que também é presente em suas filhas e filhos, nossas alunas e alunos. Nosso exercício foi no intuito de promover uma transdisciplinarização e evidenciar a possibilidade de trabalho com as mulheres negras para além de uma disciplina escolarizada.

Sabemos sim que essas práticas são trabalhos de formiguinhas, uma grande massa de profissionais que atuam na educação não teve e não tem acesso a uma formação crítica da realidade social e acabam não repassando isso em seus locais de trabalho, entretanto Evaristo ${ }^{25}$ nos lembra do poder que nós temos de falar pela máscara e ao fazer isso podemos produzir ecos que incomodem o sono dos injustos ${ }^{26}$. O movimento é importante e ele está presente desde muito tempo, temos que visibilizar.

Se torna assim, também, objetivo deste artigo possibilitar o contato de professoras e professores com práticas pedagógicas críticas, como uma contribuição a nossa formação continuada, permitindo que seja estabelecido um diálogo direto com novas formas de atuação. Somos desejosas que cada vez mais estas práticas sejam efetuadas como uma contribuição ímpar a possibilidade de a LDB 9394/96 cumprir um de seus objetivos básicos, que é formar para a cidadania, e só se forma cidadã e cidadão quem pode ser conhecedor da sua história e quem valoriza a diversidade presente em um país como o Brasil.

\footnotetext{
${ }^{25}$ EVARISTO, Conceição. Conceição Evaristo: "Nossa fala estilhaça a máscara do silêncio". Carta Capital: Maio de 2017. Entrevista concedida à Djamila Ribeiro. 2017. Disponível em https://www.cartacapital.com.br/sociedade/conceicaoevaristo-201cnossa-fala-estilhaca-a-mascara-do-silencio201d, último acesso em 30 de setembro de 2018.

${ }^{26}$ EVARISTO, Conceição. Da Grafia-Desenho De Minha Mãe Um Dos Lugares De Nascimento De Minha Escrita. 2005. Disponível em http://nossaescrevivencia.blogspot.com/2012/08/da-grafia-desenho-de-minha-mae-um-dos.html, último acesso em 30 de setembro de 2018.
} 


\section{Referências Bibliográficas}

ANDRADE, Michely Peres de. Lélia Gonzalez e o papel da educação para o feminismo negro. In Interritórios - Revista de Educação Universidade Federal de Pernambuco. V.4, N.6, 2018.

BAIRROS, Luiza. Nossos Feminismos Revisitados. In Revista Estudos Feministas, Ano 03, 2ㅇ Semestre, 1995. Pp. 458- 463

BARBOSA, Maria Carmen Silveira. Por Amor e por força: rotinas na educação infantil. Porto Alegre: Artmed, 2006.

BRASIL. Ministério da Educação. Secretaria de Educação Básica. Diretrizes curriculares nacionais para a educação infantil. Secretaria de Educação Básica. - Brasília: MEC, SEB, 2010. Disponível em: http://portal.mec.gov.br/index.php?option=com docman\&view=download\&alias=9769-

diretrizescurriculares-2012\&category slug=janeiro-2012-pdf\&ltemid=, último acesso 12 de setembro de 2018.

. Educação infantil, igualdade racial e diversidade: aspectos políticos, jurídicos, conceituais. Brasília: Ministério da Educação. Coordenação geral: Secretaria de Educação Básica/ Coordenação Geral de Educacão Infantil/ Centro de Estudos das Relações de Trabalho e Desigualdades - CEERT. São Paulo, $2012 . \quad$ Disponível em: http://portal.mec.gov.br/index.php?option=com docman\&view=download\&alias=11283-educainfantis-conceituais\&ltemid=30192, último acesso 12 de setembro de 2018.

Atualizada.

Lei de Diretrizes e Bases da Educação Nacional no 9.394, de 20 de dezembro de 1996 -

COLLINS, Patricia Hill. Aprendendo com a outsider within: a signifiação sociológica do pensamento feminista negro. In Revista Sociedade e Estado - Volume 31 Número 1 Janeiro/Abril 2016.

EVARISTO, Conceição. Da Grafia-Desenho De Minha Mãe Um Dos Lugares De Nascimento De Minha Escrita. 2005. Disponível em http://nossaescrevivencia.blogspot.com/2012/08/da-grafia-desenhode-minha-mae-um-dos.html, último acesso em 30 de setembro de 2018.

. Conceição Evaristo: "Nossa fala estilhaça a máscara do silêncio". Carta Capital: Maio de 2017. Entrevista concedida a Djamila Ribeiro. 2017. Disponível em https://www.cartacapital.com.br/sociedade/conceicao-evaristo-201cnossa-fala-estilhaca-amascara-do-silencio201d, último acesso em 30 de setembro de 2018.

GADOTTI, Moacir. Pedagogia Do Oprimido Como Pedagogia Da Autonomia E Da Esperança. In Semana Paulo Freire on line - 50 anos da Pedagogia do Oprimido. 2018.

GOMES, Nilma Lino. "Relações Étnico-raciais, educação e descolonização dos currículos". Currículo sem Fronteiras, v.12, n.1, pp. 98-109, Jan/Abr. 2012a.

GOMES, Nilma. Movimento negro e educação: ressignificando e politizando a raça. Educ. Soc., Campinas, v. 33, n. 120, p. 727-744, jul.-set. 2012b.

OLIVEIRA, Luiz Fernandes de e CANDAU, Vera Maria Ferrão. Pedagogia decolonial e educação antirracista e intercultural no Brasil. Educ. rev.[online]. 2010, vol.26, n.1, pp.15-40. http://dx.doi.org/10.1590/S0102-46982010000100002, último acesso em 05 de outubro de 2018.

PETIT, Sandra Haydée. A lei no 10.639/2003: a criação de nova abordagem de formação na 
perspectiva das africanidades. In Educ. Foco, Juiz de Fora, v. 21, n.3, p.657-684, set/dez, 2016.

PILETTI, Nelson. Estrutura e funcionamento do ensino fundamental. São Paulo: Ática, 2003.

RIBEIRO, Djamila. O que é lugar de fala? Belo Horizonte: Letramento, 2017.

SCHUMAHER, Schuma \& BRAZIL, Érico Vital. Dicionário de Mulheres do Brasil. Rio de Janeiro: Jorge Zahar Ed., 2000.

SILVA, Tomas Tadeu. Documentos de Identidade - Uma introdução às teorias do currículo. Belo Horizonte: Autêntica Editora, 2017.

SOUZA, Duda Porto de \& CARARO, Aryane. Extraordinárias - Mulheres que Revolucionaram o Brasil. São Paulo: Ed. Seguinte, 2017.

TRINDADE, Azoilda Loretto da. Fragmentos de um discurso sobre afetividade. In BRANDÃO, Ana Paula (Coord.a ). Saberes e fazeres, v.1: modos de ver. Rio de Janeiro: Fundação Roberto Marinho, 2006.

XAVIER, Giovana. Feminismo: direitos autorais de uma prática linda e preta. In Folha de S. Paulo: Julho de 2017. Agora que são elas (Coluna). Disponível em https://agoraequesaoelas.blogfolha.uol.com.br/2017/07/19/feminismo-uma-pratica-linda-epreta/, último acesso em 30 de setembro de 2018.

Carla de Oliveira Romão: Feminista. Graduada em Ciências Sociais pela UERJ. Mestre em Educação pelo Programa de Pós-graduação em Educação da UERJ. Doutoranda do Programa de Pós-graduação em Educação da UFJF na linha de pesquisa 'Gestão, Políticas Públicas e Avaliação Educacional'. Estudo as temáticas relacionadas às mulheres, feminismos, juventudes, gênero, identidade, espaço escolar e diferença.

Daiana da Silva: Mulher negra feminista, moradora da Baixada Fluminense, professora da Educação Infantil; Cientista Social formada pelo Instituto de Ciências Sociais da UERJ e mestranda em Educação do Programa de pós-graduação em Educação da UFRJ, na Linha: "Currículo, Docência e Linguagem", integrando o grupo de estudos e pesquisas: "Intelectuais Negras" da UFRJ sob orientação da Profㄹ. Dr. a Giovana Xavier.

Artigo recebido para publicação em: Outubro de 2018.

Artigo aprovado para publicação em: Maio de 2019.

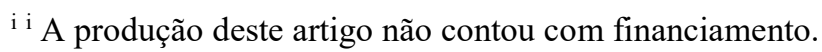

